\title{
Migrantes, madres y alumnas: las diversas presencias de mujeres bolivianas en escuelas de Córdoba (Argentina)
}

\author{
Migrant mothers and students: the diverse presences \\ of Bolivian women in Córdoba (Argentina) schools \\ María Florencia Maggi \\ CONICET/ Instituto Académico Pedagógico de Ciencias Sociales \\ Universidad Nacional de Villa María \\ florencia.maggi.88@gmail.com \\ Carina Inés Trabalón \\ CONICET/ Instituto Académico Pedagógico de Ciencias Sociales \\ Universidad Nacional de Villa María \\ cari_522@hotmail.com
}

\section{Resumen}

En el presente trabajo recuperamos desde un enfoque cualitativo, las experiencias de mujeres de origen boliviano en torno a las relaciones que establecen en diferentes espacios escolares de un barrio periférico de la ciudad de Córdoba (Argentina). Con tal propósito, analizamos las representaciones sobre migrantes bolivianas al interior de los espacios escolares del barrio: un primario de adultos del cual son alumnas, un jardín de infantes y una escuela primaria de niños/as, a los cuales asisten sus hijos/as. Al mismo tiempo, teniendo en cuenta que cada institución interpela, bajo diferentes lógicas, a dichas mujeres de acuerdo con su origen nacional y/o el de sus hijas/os, abordamos también la configuración de sus procesos identitarios a partir de las categorías "alumnas" y "madres”. Para ello, nos remitimos principalmente a las características de los procesos migratorios en la ciudad de Córdoba (y en el barrio), la dinámica particular que caracteriza a las diferentes instituciones escolares a las que haremos referencia y, algunos aspectos relativos a la condición socioeconómica del barrio en general y de la población migrante en particular.

Palabras Clave: Educación de adultos, educación intercultural, espacios escolares, procesos identitarios, Migraciones bolivianas

\section{Abstract}

The present work recovers, from a qualitative approach, the experiences of Bolivian women around the relationships established in the different school spaces of a peripheral neighborhood of the city of Córdo-

\author{
María Florencia Maggi · Carina Inés Trabalón \\ Migrantes, madres y alumnas: las diversas presenciasde mujeres bolivianas \\ en escuelas de Córdoba (Argentina). \\ Autoctonía. Revista de Ciencias Sociales e Historia, Vol. III, N² 2, Julio-Diciembre 2019, 201-223 \\ ISSN 0719-8213 \\ DOI: http://doi.org/10.23854/autoc.v3i2.123
}


ba (Argentina). With this purpose, the representations about Bolivian migrants were worked inside the school spaces of the neighborhood: a primary of adults of which they are students, a kindergarten and a primary school of children, of which they sons and daughters are students. Their identification processes will also be analyzed taking into account each institution under different logics, interpellates these women in relation to their national origin and their children' national origin. To approach the identity configuration from the categories "students" and "mothers" here we will refer mainly to: the characteristics of the migratory processes in the city of Córdoba (and in the neighborhood), the particular dynamics that characterize the different school institutions, and some aspects related to the socioeconomic condition of the neighborhood in general and of the migrant population in particular.

Keywords: Adult education, intercultural education, school spaces, Identity processes, Bolivian Migrations

\section{Una introducción desde las categorías analí- ticas en juego: procesos identitarios, migracio- nes y espacios escolares}

Con el objetivo de abordar los procesos identitarios de las mujeres bolivianas en el marco de los espacios escolares de un barrio periférico de la ciudad de Córdoba, nos interesa aquí explicitar algunas de las categorías analíticas que subyacen a nuestra perspectiva teórica.

En primer lugar, los procesos identitarios (o identificaciones) son considerados como categorías de grupos sociales, como clasificaciones que se articulan en torno a una denominación, situadas en contextos específicos (Grimson, 2011). Estas categorías se configuran de manera diferente en cada sociedad como resultado his- tórico de la distribución desigual del poder de clasificación en lo que denomina "caja de herramientas identitarias", es decir, el conjunto de categorías disponibles que permiten a sus miembros identificarse a sí mismos y a los otros. Así, las categorías clasificatorias son construcciones históricamente situadas con relación a la historia social, política y cultural arraigada en el sentido común de cada sociedad y, en este sentido, recuperamos su dimensión relacional referida, por un lado, a las categorías socialmente atribuidas con las que las personas, grupos o instituciones se refieren a sus alteridades $y$, por otro, con relación a las categorías de adscripción, de personas o grupos, a un determinado colectivo (Hall, 2003; Elias, 2003). Por su parte, esta distinción entre la identificación que los otros hacen de uno y la identificación del "yo" como 
partes constitutivas del proceso de identificación categorial será abordada aquí a partir de las nociones de procesos de heteroidentificación o interpelación y procesos de autoidentificación respectivamente (Brubaker y Cooper 2001).

Teniendo en cuenta lo expuesto, las identificaciones no pueden ser entendidas si no es con relación a los procesos sociales de los que forman parte. Resulta necesario, por lo tanto, conectar la construcción de los procesos identitarios con los aspectos estructurales que resultan relevantes para el espacio social trabajado. Si bien el análisis de la dimensión estructural supone múltiples factores a considerar, para abordar la configuración identitaria de las categorías de "alumnas" y "madres" aquí nos remitiremos principalmente a: las características de los procesos migratorios en la ciudad de Córdoba (y en el barrio), la dinámica particular que caracteriza a las diferentes instituciones escolares a las que haremos referencia y algunos aspectos relativos a la condición socioeconómica del barrio en general y de la población boliviana en particular.

En síntesis, nos proponemos abordar la configuración de los procesos de identificación atendiendo a la centralidad que cobra el origen nacional como categoría explicativa. Esto es así, ya que los grupos constituidos como argentinos/ as y bolivianos/as son simbólicamente percibidos y apreciados de manera distinta. De manera que, ser argentino/a asegura una serie de beneficios mientras que ser boliviano/a implica ocupar una posición desfavorable respecto a las je- rarquías establecidas en el imaginario social del barrio y, por lo tanto, el origen nacional resulta fundamental para entender cómo se expresan (y traducen) distintas formas de desigualdad, exclusión y diferenciación en el marco de los espacios escolares del barrio. Así, la lógica particular de cada institución educativa revela una configuración social singular que, atravesada por relaciones de poder específicas, delinean prácticas y representaciones posibles en espacios socialmente reconocidos como oficiales. En este marco, destacamos el peso significativo que tienen las representaciones de los agentes institucionales que, tal como sostiene Bourdieu (1990), cuentan con la perspectiva autorizada que refuerza el sentido común. En este sentido, retomamos del mencionado autor, la noción de nominación oficial como un extremo entre las posibles formas de violencia simbólica definida como un "acto de imposición simbólica que cuenta con toda la fuerza de lo colectivo, del consenso, del sentido común, porque es operada por un mandatario del Estado, detentador del monopolio de la violencia legítima" (Bourdieu, 1990: 294).

Los primeros estudios que abordan la relación entre la cuestión escolar y la población migrante en Argentina han privilegiado el estudio sobre las experiencias de niños en escuelas primarias. Los mismos dan cuenta de cómo circulan entre docentes y directivos representaciones prejuiciosas y estigmatizantes hacia los niños pertenecientes a diferentes grupos de migrantes, y las marcas que esas representaciones y prácticas tienen en las vidas de los niños (Sinissi, 1998; 
Neufeld y Thisted 1999; Novaro y Diez, 2011; Diez, 2011), poniendo en discusión el supuesto de integración en el paradigma educativo vigente (Domenech, 2010).

Entre las producciones académicas en Argentina existe una vacancia en el abordaje de la situación de jóvenes migrantes y, en particular, en relación a sus expectativas educativas y condición de escolaridad, por lo que los trabajos de Cerrutti y Binstock (2012), Beheran (2011) resultan novedosos. Mientras los casos de adultos migrantes en espacios escolares han sido abordados en menor medida, sí se trabaja en cambio la relación de adultos migrantes y espacios escolares en tanto padres de niños-jóvenes escolarizados. Al respecto se destaca la manera en la que se tensionan las diversas estrategias de identificación nacional de los niños, niñas y jóvenes al confluir "las expectativas familiares -en gran medida asociadas al mantenimiento de la identificación con Bolivia- y las escolares -frecuentemente vinculadas a imágenes devaluadas de este país-" (Novaro, 2014: 175).

A raíz del recorrido propuesto, nos interesa compartir en el presente trabajo algunas experiencias de mujeres bolivianas "alumnas" y "madres", para poder comprender con mayor profundidad las relaciones entre sus trayectorias migratorias y procesos identitarios.

Este artículo presenta parte de los resultados de una investigación más amplia que aborda los procesos identitarios de las mujeres bolivianas en nuestro Trabajo Final de Grado para la Licenciatura en Sociología (Maggi y Trabalón 2014). Aquí limitaremos el análisis a los aspectos que refieren a las categorías "alumnas" y "madres" en espacios escolares.

En términos metodológicos, con el propósito de comprender en el transcurso de la investigación la complejidad, el detalle y la situacionalidad de los procesos identitarios, el diseño se caracterizó por la flexibilidad propia de la investigación cualitativa. Para la elaboración de esta propuesta se analizaron 26 entrevistas realizadas en el año 2013.1 10 entrevistas semiestruturadas a agentes institucionales pertenecientes a las instituciones públicas: Jardín de Infantes y a la Escuela Primaria de niños, el Centro de Salud y el Centro de Educación de Nivel Primario de Adultos; otras 6 entrevistas semiestructuradas a vecinos argentinos; y 8 entrevistas en profundidad realizadas a mujeres bolivianas. En todos los casos decidimos reemplazar los nombres verdaderos por nombres ficticios para mantener el anonimato de nuestros interlocutores e interlocutoras. De igual forma se evitó nombrar a las instituciones involucradas y el barrio en cuestión. Este trabajo fue enriquecido por nuestra presencia constante en los espacios estudiados, donde colaboramos como docentes auxiliares. ${ }^{2}$

\section{Identificaciones social e históricamente si- tuadas. Migraciones bolivianas en Córdoba}

Considerando que los procesos identitarios deben ser pensados en el marco de las condiciones 
socioculturales e históricas de las que forman parte, resulta fundamental historizar los procesos migratorios de los migrantes de origen boliviano en Córdoba.

En la actualidad, la ciudad de Córdoba aparece como lugar de recepción de migrantes limítrofes en general, y de población boliviana en particular. Se trata de un proceso que adquiere gran intensidad, fundamentalmente, a partir de la diversificación de los destinos de estos contingentes hacía la década del 1980, cuando los migrantes limítrofes comienzan a desplazarse desde las zonas rurales hacia las periferias urbanas, observándose en los últimos años, en el caso de los bolivianos, una movilidad espacial hacia la zona sur-oeste de la ciudad (Bologna y Falcón 2012). Así, las transformaciones en los procesos migratorios repercuten en la composición poblacional de ciertos barrios de la ciudad, principalmente, barrios periféricos que comienzan a ser identificados como barrios bolivianos (Pizarro, 2011).

El barrio a considerar se encuentra ubicado en un área periférica de la zona sur de la ciudad de Córdoba, a unos 10 kilómetros del centro de la misma. En este barrio, la población migrante constituye más del $20 \%$ de la población total de la zona analizada, siendo la población boliviana la más importante cuantitativamente al representar más de la mitad de la población extranjera del barrio (54\%), seguida por la población peruana $(36 \%) y$, por último, la población proveniente de Paraguay (10\%). Si bien el flujo migratorio de origen boliviano estuvo compuesto por una población heterogénea, gran parte de la misma procedía de áreas rurales (Domenach y Celton, 1998). En la actualidad, la población de origen boliviano tiene una presencia muy significativa en la ciudad de Córdoba y alrededores. En estos barrios periféricos (tanto espacial como socialmente) de la ciudad de Córdoba, residen la mayoría de los migrantes bolivianos de condición socioeconómica desfavorable (Pizarro, 2011).

En investigaciones anteriores (Maggi y Trabalón, 2015), hemos indagado cómo en este barrio de la ciudad, la presencia de migrantes de dicho origen configura en múltiples sentidos las relaciones sociales, atravesadas en gran medida por el rechazo a bolivianos. Nos detuvimos en las dinámicas entre vecinos locales y migrantes, y dimos cuenta de que, al ser los servicios que las instituciones prestan "estratégicos" por ser valiosos y escasos, hay entre los vecinos una puja por obtenerlos, cuya dimensión conflictiva se plantea a partir de una diferenciación que se constituye como tal en función de la nacionalidad argentina/boliviana (o nacionales y migrantes). Las dinámicas del barrio se inscriben en un contexto histórico marcado por el rechazo al inmigrante limítrofe en argentina. Tal es así que, en el imaginario social argentino, la población de origen boliviano ocupa la posición más desfavorable con relación a las jerarquías étnicas establecidas (Grimson, 2006), haciendo necesario considerar dichos procesos teniendo siempre presente la existencia de desigualdades constituidas sobre bases racializadas y distintos fundamentos xenófobos (Caggiano, 2008). Para 
el presente trabajo, nos interesa en particular recuperar cómo opera esta lógica al interior de las instituciones educativas, y cómo interviene en la configuración identitaria de las mujeres bolivianas.

\section{Un proyecto de Educación Intercultural en una Escuela de adultos}

El Centro de Educación de Nivel Primario de Adultos (CENPA) 4 , se encuadra en la modalidad escolar Permanente de Jóvenes y Adultos, que contempla la organización de los educandos según contenidos incorporados en instancias previas de formación, a partir de tres períodos escolares: Alfabetización, Primer Ciclo y Segundo Ciclo.

Al momento de la inscripción escolar, por iniciativa de las docentes a cargo, se realiza un diagnóstico para poder evaluar el nivel de escolarización que le corresponde comenzar al futuro alumno. 5 Para la modalidad de jóvenes y adultos/as, la situación de diagnóstico es más compleja que en la modalidad de menores, dado que quienes se inscriben son personas mayores de edad que pueden llevar varios años alejados de las instituciones educativas, incluso sin llegar a recordar hasta qué año se cursó. A estas circunstancias se suman los cambios normativos que pudieron ocurrir en el medio, y las diferencias jurisdicciones, entre ellas internacionales, que regulan o reconocen la formación previa. En el caso de los y las jóvenes, por el contrario, pese a contar con los boletines oficiales en grados avanzados, "te encontrás con niños que escriben su nombre nomás y de memoria, ni siquiera lo saben leer" (Marina, docente del CENPA).

En este sentido, la estrategia por la que optó el cuerpo docente consiste en diagnosticar a partir de saberes cotidianos vinculados a los contenidos curriculares. Para matemática, por ejemplo, se considera el uso de dinero, mediante el planteo de "situaciones de compra" y contabilización de billetes y monedas. Para lengua, se evalúa el nivel al comenzar mediante la lectura en tres instancias graduales de complejización: primero se pide la lectura de palabras sueltas simples, un texto muy breve en imprenta minúscula y posteriormente un texto corto en cursiva. Mediante esta técnica de diagnóstico hay por parte de las docentes un reconocimiento de los saberes de los jóvenes y adultos, por sobre los formalismos institucionales.

También durante el diagnóstico, se realiza una entrevista donde se consulta sobre experiencias laborales, la trayectoria escolar y la situación familiar. A partir del trabajo de indagación realizado la escuela comienza a ensayar en el año 2005, una propuesta de educación intercultural. El mismo surge del reconocimiento de la diversidad cultural presente en la comunidad a la que la institución pertenece, como así también a la población que constituye la matrícula del propio centro. Por entonces, el $33 \%$ de la población escolar era migrante limítrofe (26\% procede de Bolivia, sumado al 7\% de Perú), y del $66 \%$ restante, el $41 \%$ eran migrantes internos. De este 
modo, se consideró necesario considerar esta diversidad en el planteo de la acción educativa, comprendiéndola desde la posibilidad de "construir y valorar saberes; de comprender diferencias y conflictos; y de desarrollar actitudes de respeto y tolerancia" (Cenpa, 2009).

El alcance esperado no se restringía a la institución, sino que se proponían talleres abiertos a la comunidad. Estos espacios buscaban, por un lado, articular los contenidos curriculares mediante lógicas de trabajo más horizontales y, a su vez, mejorar las relaciones sociales del barrio. Entre los objetivos del proyecto se plantea: "Los destinatarios de la Ed. Intercultural son tanto las personas pertenecientes a los diferentes colectivos étnicos como los miembros de la población autóctona. Esta apuesta pedagógica intenta que ambos grupos: a) Se conozcan y valoren las diferentes culturas. b) Modifiquen estereotipos y prejuicios; y c) Promuevan actitudes, conductas y cambios sociales positivos que eviten la discriminación y mejoren sus condiciones de vida." (CENPA, 2009).

Los talleres que fueron desarrollándose en el marco de dicho proyecto institucional entre 2005 y 2013 fueron: Taller de danza - Expresión corporal; Taller de canto coral; Taller de quechua; Taller de salud; Taller de producción de recetas y elaboración de comidas; Taller de hilado artesanal; Taller de producción de contenidos para revista "Tierra de todos"6.

Finalmente, se proponía la realización de una fiesta en el cual se presentan los trabajos realizados en los distintos talleres. En efecto, desde 2005 se realiza en red con otras instituciones barriales el llamado Encuentro Intercultural y Fiesta Patronal. El mismo comienza con una procesión religiosa en la que se traslada al santo patrono del barrio, hasta la calle frente a la capilla y se oficia una misa, dando inicio a la fiesta que cuenta con un escenario general para números artísticos musicales y de danzas folclóricas y bailes populares de Bolivia, Perú, Paraguay y Argentina. Además de mostrar el trabajo que llevan las distintas instituciones en sus stands, hay puestos con comidas típicas y artesanías.

En trabajos anteriores, nos hemos centrado en cómo se configuran las relaciones barriales entre migrantes y locales. Allí dimos cuenta que de que dicho encuentro más que ser un ejemplo de convivencia armoniosa de las relaciones interculturales en el barrio, era un cristalizador de las diferencias y conflictos entre vecinos a partir de los orígenes clasificados en términos regionales y/o nacioanles. De hecho, es precisamente una propuesta que surge de la preocupación de las instituciones que lo organizan, pretendiendo así promover mayor integración comunitaria. Por otra parte, este accionar mediador que lleva adelante el CENPA junto al Centro de Salud es críticamente recuperado por algunos vecinos locales, quienes parten del supuesto "favoritismo" que migrantes tendrían, para justificar la "bronca" y actos discriminatorios para con bolivianos. Paradójicamente, entonces, aquellas acciones que buscan minimizar los conflictos y 
que podrían leerse como "políticas institucionales de discriminación afirmativa”, al ser recuperadas como un favoritismo -y por lo tanto como una focalización indebida- contribuyen a intensificar la tensión entre vecinos de diferentes nacionalidades (Maggi y Trabalón, 2015).

Por otra parte, esta lógica de integración para con la población migrante no es la única que establecen agentes institucionales de espacios escolares, por lo que la participación en dicho encuentro por parte de otras instituciones se reduce a "mostrar" trabajos que algunos docentes aisladamente han realizado. Asimismo, con relación a los talleres que se llevan adelante desde el CENPA, las docentes resaltan la dificultad que se asume al trabajar desde los espacios de taller. En este sentido, aunque se consideraba valiosa la modalidad por permitir incorporar una diversidad de saberes a partir de una dinámica horizontal de trabajo con los educandos, estos mecanismos también implicaron, en muchas ocasiones, que los y las alumnas evaluaran esos espacios como "extra escolares" (en el sentido de ajenos al aprendizaje típicamente escolar) $\mathrm{u}$ "ociosos", perdiendo el verdadero sentido de su incorporación.

\subsection{Las mujeres bolivianas como alumnas}

"J: los varones han salido secundario, sí. Mujeres no, somos tres mujeres que no. (...) yo quise estudiar, porque mi mamá no quiso. Y tal vez por eso, no sé yo no sé. Yo no puedo comprender bien (...)
E: y la escuela quedaba cerca?

J: primaria sí. Había para caminar 20 minutos. Y secundaria más lejos" (Fragmento de entrevista con Julia, alumna boliviana del CENPA)

En base a este relevamiento del diagnóstico de la institución, a estadísticas oficiales, junto con entrevistas y registros de campos con las alumnas bolivianas y docentes, reconstruimos sus trayectorias educativas.

Sobre la situación de escolaridad de la población del barrio, si se considera el máximo nivel de instrucción alcanzado de las personas con más de 15 años, las mujeres migrantes de origen boliviano son las que registran el valor porcentual más alto de nula escolarización o primario incompleto en relación a otros colectivos nacionales migrantes y a locales. Alrededor del 35\% de las mujeres bolivianas nunca asistió $(17 \%)$ o no terminó la primaria $(18 \%)^{7}$.

En concordancia, de las 26 personas de entre 13 y 63 años que asisten al CENPA, 18 son mujeres bolivianas, es decir, alrededor del $70 \%$ de la matrícula escolar8. Por el relevamiento institucional también se conoce que casi el 30\% (7 alumnas) no habían asistido nunca a un establecimiento educativo. De los alumnos que sí fueron escolarizados y que tuvieron por diversas razones que abandonar la escuela, más de la mitad no repitió nunca; e igual cantidad repitieron una o dos veces. ${ }^{9}$ 


\section{Foto 1: Abanderadas del CENPA en acto de cie- rre lectivo 2013.}

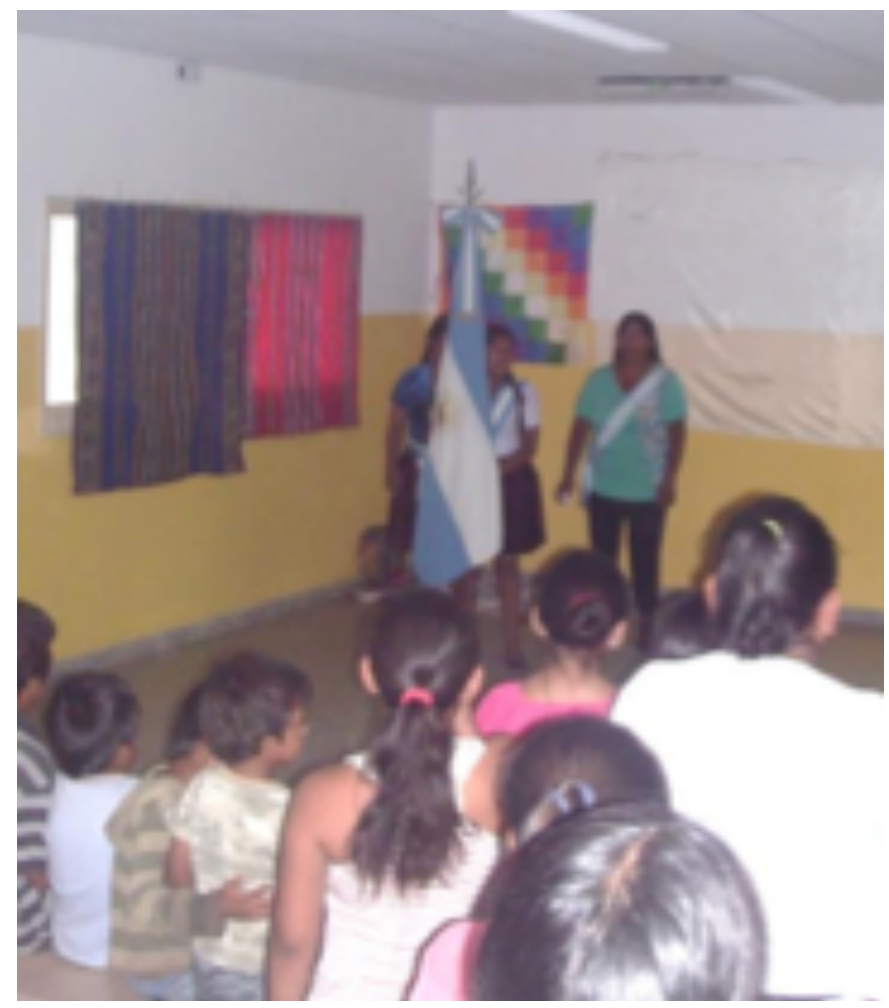

Fuente: Fotografía nuestra. 11/12/2013

En el caso de las alumnas bolivianas, los motivos de deserción o los motivos por los que algunas alumnas nunca asistieron se fundan principalmente en problemáticas de desigualdad socio-económicas y de género. En estos casos, es muy recurrente la explicación a partir de la necesidad de contribuir en el trabajo familiar en contextos de ruralidad, o en un sentido parecido, por no poder afrontar los costos en términos económicos que conllevan asistir a la escuela, principalmente el transporte por las lejanas distancias entre el hogar y las intituciones y los materiales de estudio.
Las complicaciones económicas deben ser comprendidas en relación a la existencia de asimetrías de género en las estrategias familiares para definir la formación educativa de los menores. Así, las alumnas bolivianas en sus relatos comentan que, si bien tanto niños como niñas comenzaban la educación primaria, una vez que las niñas aprendían a leer y escribir (en primero o segundo grado) las familias las dejaban de mandar a la escuela argumentando explícitamente que por ser mujer no iban a necesitar saber más (para concretarse en tareas de cuidado, aseo del hogar, cuidado de animales, textiles y cosechas) mientras que los varones sí continuaban sus estudios. En relación a dicha intersección entre condición social y género, hay que contemplar también la pertenencia regional, siendo las asimetrías de género más acentuadas entre las alumnas de origen regional rural. En este sentido, las trayectorias educativas de las que provienen de zonas rurales de Bolivia suelen ser más acotadas para las mujeres que para los varones. ${ }^{10} \mathrm{Al}$ respecto, una entrevistada (citada al comienzo del apartado) manifiesta que los varones de su familia han terminado todo el secundario mientras que las mujeres -tres hermanasno han podido terminar el primario porque, por más que ellas querían darle continuidad a sus estudios, la madre no se los permitió.

En segundo lugar, las docentes refieren a cómo la desigualdad de género incide en las diferentes estrategias que adoptan las alumnas para asistir a clases, concretamente las maestras sostienen que muchas de las mujeres bolivianas piden de 
manera reiterada "licencia" para faltar argumentando que sus maridos vuelven del trabajo estacional realizado en otras ciudades al hogar de manera que, muchas veces, los esposos no están enterados de que asisten a la escuela y, por lo tanto, su asistencia es irregular y depende de los trabajos temporarios de los varones.

Una última cuestión a tener en cuenta, además de las condiciones de vulnerabilidad económica, las asimetrías de género y la pertenencia regional, refiere precisamente al proceso migratorio. En el caso de la alumna boliviana más joven (13 años), por haber migrado en edad escolar, interrumpe su formación escolar. De modo que, una vez llegada a Córdoba, se complica su continuidad en el primario de niños por la diferencia de edad con respecto al grado que le es asignado. Por tanto, su inserción en el primer ciclo del primario de adultos se da pese a ser menor. ${ }^{11}$

\subsubsection{Comenzar o retomar la escuela}

"quiero aprender más, así puedo ayudar a mis hijos porque no sé.” (Luisa, alumna boliviana del CENPA)

“quiero aprender, pues si no voy a estar así burra toda, no voy a estar preguntando a la gente 'qué dice esto' así iba yo al centro, así ya llego así más 'qué dice esto, y donde es' Ay! Cómo andaba yo" (Bernarda, alumna boliviana del CENPA)

Comenzar o retomar la escuela es una decisión que, según comentan muchas de las mujeres bolivianas adultas se funda en la necesidad de “ayudar a sus hijos". Así, una de las mujeres bolivianas comentaba su frustración cuando sus hijos le pedían ayuda con las tareas escolares y ella no podía dársela, resaltando además que querer aprender para enseñar quizás ya no le serviría para con sus hijos, pero al menos lo podría hacer para sus nietos.

Cabe mencionar también que, retomar el estudio escolar, tal como mencionan las mujeres bolivianas entrevistadas, (en congruencia con lo manifestado por los agentes institucionales), es considerado como una estrategia de integración en la sociedad receptora entendiendo que las herramientas que ésta proporciona pueden servir para la resolución de diferentes situaciones que se plantean en destino. Las diversas razones van desde poder leer los nombres de las calles para ubicarse cuando salen del barrio, y poder hacerse entender al realizar las compras cotidianas (cuando los nombres de las verduras o cortes de carne por ejemplo, no son los mismos que los empleados en Bolivia); hasta la resolución de trámites incluidos entre las tareas de cuidado.

Si bien no aparece como motivo principal de inscripción en la primaria continuar estudiando, según el relevamiento que durante el diagnóstico realizan desde la institución, hay un interés mayoritario por seguir con los estudios secundarios así como también por recibir capacitación laboral (de entre el 70 y 75 \%). En caso de los interesados en realizar alguna formación laboral, se les consultó sobre cuáles oficios qui- 
sieran aprender, las respuestas más reiteradas fueron costurería, tejidos, cocina/repostería/ panadería y computación. ${ }^{12}$

Al momento del diagnóstico, sólo tres mujeres de origen boliviano respondieron tener un trabajo permanente como empleadas domésticas (limpieza y cuidado de niños) y cuatro alumnas bolivianas contar con trabajos temporarios (dos de ellas a la venta de tejidos artesanales propios; y las dos restantes a la elaboración y venta de "viandas").

Sin embargo, en entrevistas con las mujeres que decían no trabajar, comentaban sobre una serie de trabajos informales o temporales sin paga en dinero. Los casos más ejemplificadores son los de la recolección de papas (limpiado de las quintas donde se cosecha papa, llevándose las papas de tamaño no comerciable) y del carpido (limpieza de yuyos en las quintas).

\subsubsection{Apropiarse de la escuela}

"la seño también nos ha indicado, no tienen que tener miedo ustedes, igual somos humanos también, igual como ustedes, nos decían, y después ya no tenía miedo" (Ludmila, alumna boliviana del CENPA)

La escuela de adultos además de ser visualizada como una posibilidad de inserción en la sociedad y una instancia de formación para contribuir en la educación de sus hijos, es un espacio valorado por las mujeres en sí mismo. Las dinámicas esco- lares que propone el cuerpo docente, permiten que las mujeres que también son madre asistan a clase con sus hijos. Este aspecto es crucial para garantizar el sostenimiento de la asistencia. Según Magliano (2007), las experiencias de las migrantes bolivianas en la sociedad de llegada se comprenden en el marco de una doble desigualdad social: no solo la inserción laboral en mercados de trabajo precarizados y feminizados, sino también, el de la reproducción de roles de género dentro de las unidades familiares, asociados al trabajo reproductivo y al cuidado de otros/as como una obligación moral. Por tanto la categorización que aquí relevamos para pensar a las mujeres en relación a las instituciones educativas, a saber, alumnas en la escuela de adultos, y madres de los alumnos en la escuela de niños no son excluyentes. Las mujeres que son madres, principalmente aquellas que tienen niños que todavía no se encuentran en edad escolar, cargan con la doble responsabilidad de cuidado durante su propia escolaridad. Podríamos pensar entonces la relación cíclica entre "aprender para enseñar" atravesada por "aprender cuidando".

\section{Foto 2: Alumna del CENPA con su hijo durante la clase de Plástica ${ }^{13}$}




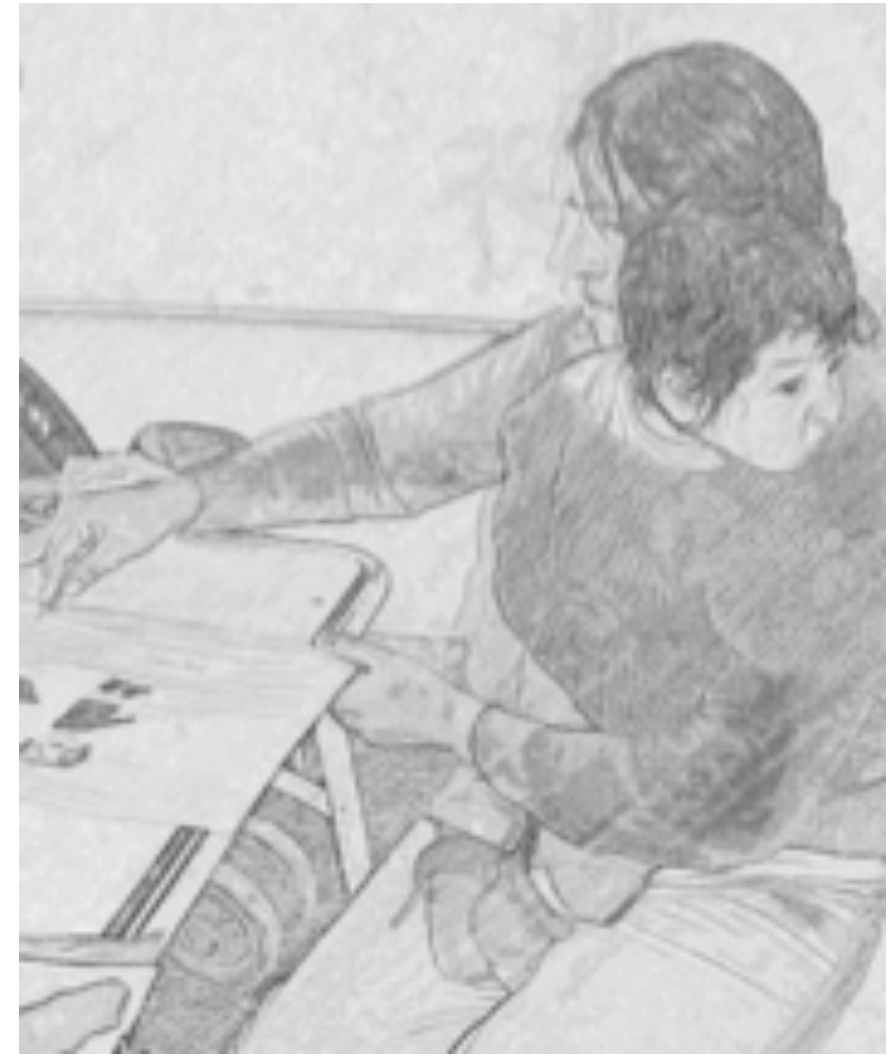

Fuente: Fotografía nuestra. 26/09/2013

Por otra parte es importante resaltar una relación que se reitera en las entrevistas entre la inseguridad que se vive en el transitar el barrio y la continuidad en el cursado. Es decir, hay una generalizada preocupación de ser víctimas de una situación de robo tanto mientras se camina en el barrio, como en dejar sola la vivienda. Incluso en algunos casos, se destaca el hecho de que es precisamente en el horario de cursado (13 a 17 horas) o por la noche, los momentos de mayor riesgo. Sin embargo, la permanencia en el espacio se sostiene.

Nos preguntamos por las relaciones que la institución habilita en este contexto. Si se considera la alta matrícula de mujeres migrantes del mismo origen -que por otra parte están vinculadas en redes de parestezco en muchos casos, y de vecinazgos en todos- en un espacio predispuesto a escuchar sus vivencias y necesidades, contrasta con las relaciones conflictivas con locales en otros contextos. En este sentido, el lugar de las docentes es positivamente valorado. Además de representar una voz legítima en el campo "escolar", son referentes a quienes se pueden consultar cuestiones propias de la sociedad receptora, o incluso de la vida personal. Por citar un ejemplo, en una de las entrevistas con una de las mujeres, conversando sobre su situación laboral, nos comentaba la poca paga que había recibido en un taller de costura y cómo este trabajo afectaba su salud, por lo que decide dejar ese trabajo animada por la recomendación de su docente "Me dijo la seño, déjale si te hace gastar tus pulmones, te va a hacer mal, y lo dejé y si... mi marido también no quiere que trabaje porque yo no más quería trabajar" (Luisa).

La importancia que le asignan a ese punto de vista "legítimo", a nuestro entender, debe ser comprendida en el marco de cómo se configuran las relaciones de dichas mujeres en el contexto posmigratorio.

\section{La diferencia como problema en las institu- ciones educativas para menores}

“[entre los alumnos] descalificativos 'bolita', otros sobrenombres... 'papas negras'... Pasó una vez en la clase de educación física que un chiqui- 
to se cayó, tropezó y se cayó por allá porque hay como piedras allá en el patio y entonces la profe de educación física fue a levantarlo y entonces un niñito le dice: 'no lo ayude porque es boliviano'.” (Alicia, docente del Primario de Niños).

De acuerdo con lo registrado en las entrevistas, se expresa una distinción entre el accionar de la escuela para adultos y el de la escuela primaria y jardín de infantes, con respecto a las relaciones que dentro de cada institución se establecen con la población de origen boliviano. A diferencia del CENPA, en el caso del primario de niños y el jardín de infantes, no hay una propuesta institucional que aborde específicamente la cuestión intercultural. En este sentido, las reiteradas repitencia o las dificultades con el aprendizaje asociado al uso en la escuela de la lengua castellana como única lengua materna de niños provenientes de familias bolivianas no son problematizadas institucionalmente aunque tanto directivos como docentes lo planteen al ser entrevistados. Pero las dificultades de abordarlo no se agotan en la propia institución, en 2007 el primario de niños y el CENPA contaron con una auxiliar docente de origen boliviano que comenzó a trabajar articuladamente con un Instituto de formación terciaria. Su participación en la escuela no fue reglamentada bajo la figura que está prevista en la Ley 26.206 desde la modalidad Intercultural Bilingüe, sino que desde el Ministerio de Educación provincial se le asignó un cargo de preceptora de un terciario en la que se desempeñaba como docente. Cuando por conflictos internos, hay cambio provisorio de autoridades, la directora interina desconoce la articulación, y a falta de claridad, la auxiliar docente deja de poder cumplir sus horas en las instituciones del barrio sin retomarse en los posteriores años. Este que ha sido uno de los intentos más concretos de abordaje intercultural en la institución queda trunco desde entonces.

En lo que respecta al trato entre pares, en las dos instituciones educativas para menores, tanto los agentes institucionales como las madres de los menores, dan cuentan de las situaciones de discriminación que padecen los niños migrantes o hijos de migrantes por parte de niños de familias argentinas. Algunos docentes recuperan preocupados este tipo de situaciones que los tienen como testigos o bien a partir de lo que los mismos alumnos expresan y que ellos nos comentan en nuestras entrevistas -como podemos observar en las citas arriba de fragmentos de entrevistas con docentes de la escuela primaria-.

Por otra parte, también se registran en las entrevistas casos donde quienes protagonizan las situaciones de discriminación son docentes:

"Entre los niños y entre un grupo de docentes. (...) La descalificación, el hecho de que porque vos estás en mi país tenés que aprender y hacer lo que mi país te ofrece y no tenés opciones a opinar o a decir eso no es así." (Alicia, docente del Primario de Niños).

"Esta cuestión que uno ve, bueno, esto de sumisión de las personas que son de Bolivia, o sea, 
ellas esperan y no pasa nada. En cambio, las mujeres que son de acá de Argentina hay una reacción que ella conoce y sabe. Entonces, ella no juega con los tiempos de las mujeres y en cambio con las de Bolivia sí... (Paula docente del Primario de Niños).

En este sentido, la recuperación crítica de docentes y directivos sobre el accionar de colegas (aquí fundamentalmente la escuela primaria) permite dar cuenta cómo opera el poder simbólico, es decir, la palabra autorizada en detrimento del grupo conformado por bolivianos e hijos de bolivianos. Sucede que, este tipo de prácticas que en entrevistas son cuestionadas por colegas, en cambio, pueden posiblemente no tener esta instancia de lectura crítica para niños o vecinos para quienes los docentes -"maestros"- son autoridades institucionales que cuentan con la perspectiva autorizada que refuerza el sentido común.

\subsection{Las mujeres bolivianas como madres de alumnos}

Las interpelaciones sobre la figura de la mujer de origen boliviano como madre son consideradas aquí problematizando el supuesto rol pasivo de la mujer en el proceso migratorio, teniendo presente la importancia que implica su desempeño en la reproducción cultural (y material) de la unidad familiar y, asimismo, en la configuración de sus procesos identitarios. Se entiende, además, que su accionar resulta decisivo con respecto a los cambios y continuidades de distintos aspectos culturales relacionados, por ejemplo, con la alimentación de los hijos, la vestimenta, la enseñanza de la lengua materna y la realización de diferentes actividades, ritos o celebraciones, entre otros.

Teniendo como horizonte, entonces, los diferentes procesos sociales que atraviesan las identificaciones, en este apartado nos referiremos: en primer lugar, al marco social de desigualdad que caracteriza a los procesos migratorios analizados y, en segundo lugar, al marco cultural, esto es, a las diferencias que aparecen (y se entienden) producto de la pertenencia a configuraciones culturales distintas. Tanto el marco social como el cultural son abordados desde una dimensión histórica que se propone (nuevamente) articular las representaciones que los agentes institucionales argentinos tienen sobre las mujeres bolivianas, en este caso en tanto "madres", en diálogo y tensión con las representaciones que las mujeres bolivianas tienen de sí mismas. De acuerdo con esta distinción analítica, trabajaremos a partir de dos cuestiones que se repiten de manera constante en las entrevistas realizadas: por un lado, las representaciones referidas a la manera en que las mujeres bolivianas educan o "crían" a sus hijos, haciendo énfasis en las condiciones del marco cultural y, por otro lado, las expresiones que surgen con relación al valor otorgado a la educación de sus hijos, haciendo referencia sobre todo al marco socio-económico.

\subsubsection{Representaciones sobre "la madre boli- viana"}


"Es más, muchas de las chicas me dicen que por ahí, que ven mucho más intereses en el boliviano para que el chico se eduque a que un argentino. El argentino por lo general son los que más faltas tienen, lo que menos interés" (Graciela, docente Jardín de Infantes).

"como que hay mucha expectativa puesta en el niño. Ellos vienen buscando esta cuestión de poder mejorar su calidad de vida y en esa expectativa está el hijo, de que estudie, de que pueda integrarse a la sociedad argentina y de comprometerse" (Paula, docente Primario de Niños).

Con respecto al primer punto, la forma en que las mujeres de origen boliviano educan a sus hijos, los agentes institucionales del ámbito de la educación, en particular desde la escuela primaria, expresan valoraciones positivas en cuanto al respeto y la obediencia que tendrían los niños para con las madres bolivianas. Este hecho es contrapuesto con el mal trato que tendrían los niños argentinos con las madres argentinas y los adultos en general, caracterizados en los relatos por ser desobedientes, insultar y dirigirse de forma irrespetuosa. En las representaciones analizadas estos principios de diferenciación son explicados por la pertenencia a una "cultura" distinta. Es decir, se atribuyen diferentes "formas de educar" y "formas de criar" a los hijos de acuerdo al origen nacional. El marco cultural, en tanto referencia a configuraciones culturales como base para la comprensión de prácticas, permite así una primera comprensión de las distintas representaciones en torno a las "formas de ser madre”.

Asimismo, tiene lugar en los relatos la mención a otras prácticas relacionadas con la educación o con formas de crianza, como por ejemplo, con respecto al uso del aguayo donde aparece preocupación porque no se "caiga" el niño o "le pase algo", y referido a las prácticas de salud, donde se presentan apreciaciones tanto positivas como negativas con relación a la medicina no occidental para el tratamiento de ciertas enfermedades de los niños.

En todos los casos, la referencia a las prácticas de las mujeres bolivianas se funda en representaciones culturalistas que desde nuestra perspectiva teórica son entendidas como diferencias de regímenes de sentido. Así, la noción de configuración cultural resulta particularmente útil en tanto habilita a pensar las relaciones entre regímenes de sentido y espacios ( $\mathrm{y}$ no entre individuos y rasgos). Cada configuración cultural supone la existencia de tramas simbólicas compartidas, por lo que, "las personas que habitan una configuración cultural y no comparten uno u otro rasgo frecuente significan de un modo distinto ese rasgo y esa diferencia que alguien que habita otra configuración” (Grimson, 2011: 189).

Por otra parte, con relación al segundo grupo de representaciones a analizar, referidas al valor que otorgan las madres bolivianas a la educación de sus hijos, se observa cierto consenso sobre las caracterizaciones que se hacen al respecto. La mayoría de los docentes y directivos entrevista- 
dos coinciden en la importancia que le dan las mujeres bolivianas a la educación de sus hijos en contraposición con el escaso interés que demostrarían las madres argentinas. De acuerdo con los relatos, es posible conectar el valor dado por las mujeres de origen boliviano a la educación de sus hijos con varios aspectos.

En primer lugar, se destaca el valor de la educación expresado en el acompañamiento y preocupación de las madres bolivianas por sus hijos. Según los entrevistados, las madres bolivianas se acercan constantemente a la escuela donde asisten sus hijos para estar al tanto de cómo es su desempeño escolar tanto en el nivel inicial como en el nivel primario. Así, las maestras destacan cómo las mujeres bolivianas están atentas a las demandas de la escuela primaria o jardín de infantes y son muy responsables respecto a la asistencia de sus hijos. Al mismo tiempo, se manifiesta de manera contraria que madres argentinas se preocuparían y acompañarían menos a sus hijos y éstos, a su vez, tendrían más faltas.

En segundo lugar, teniendo en cuenta el marco social configurado por las relaciones que se establecen entre procesos migratorios y contextos de pobreza de los lugares de origen y destino, nos interesa conectar el valor que las mujeres le dan a la educación con la proyección de una mejor calidad de vida. De esta forma, las diferentes representaciones sobre el valor de la educación son fundamentadas por los agentes institucionales en función de las expectativas que tendrían las madres bolivianas con respecto a la po- sibilidad de una mejor calidad de vida para sus hijos. Según los relatos, la educación se transforma en un medio para ello y, simultáneamente, en una forma privilegiada de inserción en la sociedad receptora. Una de las maestras de la escuela primaria, por ejemplo, comentaba cómo las mujeres vienen de Bolivia buscando una mejor calidad de vida y en ese proceso, la expectativa está puesta en el hijo y se vehiculiza a través de la educación como modo de integración a la sociedad. Así, se ejemplifica esta situación a partir de distintos hechos puntuales como el caso de una mujer boliviana que llega a vivir al barrio a mitad de año y como no puede anotar a su hijo en la escuela, aconsejada por la maestra del primario, lleva a su hijo para que asista a talleres de formación que se dictan en la capilla del barrio.

Las expectativas, tal como manifiestan las maestras del primario para adultos, también se manifiestan en la continuidad de los estudios luego de la primaria, por ejemplo, en la acción de invertir para que cursen el secundario en los que se consideran "buenos colegios". Lo cual es visto como una marca distintiva de las estrategias adoptadas por las madres bolivianas con relación a la formación educativa de sus hijos ${ }^{14}$.

\subsubsection{La propia percepción como "madres"}

“distinto, eso sí que es distinto... nosotros somos bien, educamos a los chicos, no hurgar nada y no hablar malas palabras... ...En el colegio también, no pelear, no pelear, bien estrictos en el colegio. ¡Acá no! No respetan ni a las seños, 
están escupiendo, están peleando, ¡fu!”(Bernarda, madre boliviana).

"yo siempre a su maestra de mi hija siempre por celular, por mensaje hablamos, siempre yo le pregunto 'cómo está mi hija' 'qué le hace falta' yo no le pregunto a su seño de mí, ahora por lo menos le mandé mensaje "hasta cuándo hay clases y cuándo entregan las libretas'" (Julia, madre boliviana).

A continuación, nos proponemos contraponer los dos puntos trabajados en relación a las interpelaciones sobre la figura de la madre boliviana para poder analizar de qué manera las mujeres bolivianas se autoidentifican como madres con respecto a: primer lugar, la educación/"crianza" de sus hijos y, en segundo lugar, el valor que le otorgan a la educación de sus hijos, atendiendo a las condiciones a condiciones socioeconómicas.

Cómo pudimos dar cuenta en las representaciones de los agentes institucionales del ámbito de la educación, entre las interpelaciones con respecto a la figura de la madre boliviana se incluyen valoraciones positivas que aluden al respeto y la obediencia que tienen los niños para con las madres bolivianas a diferencia del (mal) trato que tendrían los niños con las madres argentinas y en general con los adultos. Estas valoraciones, fundamentadas en principios de diferenciación de acuerdo a la pertenencia a configuraciones culturales distintas, encuentran su correlato en las identificaciones que, como madres, tienen las propias mujeres bolivianas. De esta ma- nera, expresan una valoración positiva que las distingue de las madres argentinas. Sobre esta diferencia, manifiesta en el ámbito educativo en particular y, en comparación con el contexto del país de origen, una de las entrevistadas relata cómo las madres bolivianas educan "mejor" a sus hijos enseñándoles a no "hurgar" y no decir malas palabras y contando cómo en las escuelas primarias de Bolivia (de la zona rural) tenían un control mucho más estricto de la conducta de los niños no dejándolos, por ejemplo, pelear, escupir y haciéndoles respetar a lo/as maestro/as -a diferencia de lo que ocurriría en Argentina-. Observación compartida por otra entrevistada, quién, además, advierte sobre el uso de ciertas palabras (como referirse a la madre como "vieja”) que, a su criterio, suponen una falta de respeto de los niños para con los adultos, señalando este hecho como una característica de los niños argentinos, asociado a la falta de responsabilidad de los adultos (argentinos) en la educación de sus hijos.

Si bien la mayoría de las mujeres bolivianas se reconocen como "mejores" madres que las argentinas en los aspectos analizados (en congruencia a los dichos de los agentes institucionales sobre el respeto y la obediencia) aparecen también, diferenciaciones referidas al conjunto de mujeres bolivianas sobre el cuidado de la higiene de los hijos. Así, en la definición de criterios de higiene las mujeres bolivianas encuentran diferencias en relación a la población argentina, pero sobre todo como aspecto característico de algunas madres paisanas para con sus hijos, marcando, al 
mismo tiempo, un principio de diferenciación al interior del grupo (teóricamente construido) de las mujeres bolivianas.

Por otra parte, en relación a la segunda cuestión a analizar, el valor que le otorgan las mujeres bolivianas a la educación de sus hijos, observamos que el reconocimiento y las apreciaciones positivas de parte agentes institucionales del barrio también tienen su correspondencia en las expresiones de las mujeres bolivianas sobre este tema. En los sucesivos casos se afirma la importancia que tiene para las mujeres bolivianas que sus hijos estudien. Así, el valor de la educación se expresa, por ejemplo, en el acompañamiento y preocupación de las madres sobre el desempeño de sus hijos en la escuela. En uno de los relatos, la entrevistada comenta cómo se comunica permanentemente por celular con la maestra de su hija para consultarle "cómo le va", "qué le hace falta”, "cuándo entregan las libretas”, etc.

\section{Reflexiones finales}

Mediante el presente trabajo recuperamos las experiencias de mujeres migrantes adultas en las distintas instituciones educativas de uno de los denominados barrios bolivianos de la periferia de la Ciudad de Córdoba.

En términos institucionales, cabe desatacar la diferencia de enfoques desde los que se aborda la interculturalidad de la escuela para adultos y el de la escuela primaria y jardín de infantes, con respecto a las relaciones que dentro de cada ins- titución se establecen con la población de origen boliviano. Aunque las instituciones no pueden reglar la totalidad de las prácticas que en ellas se desenvuelven, son espacios donde se habilitan o no ciertos discursos y formas de interacción. En este sentido, observamos que mientras que desde la escuela de adultos se ensayan -con distintas dificultades- alternativas educativas para recuperar y poner en valor los saberes de las alumnas migrantes; en las instituciones escolares para menores se registran prácticas de maltrato y discriminación entre pares (primaria y jardín), e incluso de docentes para con alumnos y familiares bolivianos (en el caso del primario). Es importante resaltar que ésta no es una situación generalizada en las instituciones de menores, pero que en tanto se expresan en reiteradas entrevistas, tienen una importancia particular por el lugar autorizado que ocupan los y las docentes en la comunidad barrial.

Por otra parte, las relaciones posibles en la escuela primaria de adultos basadas en el respeto $\mathrm{y}$ afecto que docentes garantizan, facilitaban la permanencia en el espacio. Al momento de la investigación, el $70 \%$ de la matrícula escolar estaba constituido por mujeres migrantes bolivianas. El ingreso a la escuela se comprende al reconstruir las trayectorias escolares truncadas o nunca comenzadas de dichas mujeres. Las mismas se han dado en el marco de condiciones de vulnerabilidad económica en Bolivia, de asimetrías de género, e incluso por el proceso migratorio mismo (para quienes migraron durante la escolarización). 
En lo que respecta a los procesos identitarios de las mujeres migrantes relacionado con sus experiencias como alumnas y como madres de niños/as escolarizados, consideramos que los sentidos que se les otorgan a la educación, son reconfigurados en el contexto posmigratorio. En este marco se establece un nuevo esquema de expectativas asociadas a las nuevas condiciones del entorno social. Si bien las madres bolivianas no explicitan la consideración de la escuela para sus hijos como depositaria de aspiraciones para una mejor calidad de vida, las distintas representaciones analizadas dan cuenta de la importancia asignada en la configuración de las estrategias para la inserción de sus hijos/as. En relación a éste aspecto, y a las "formas de crianza" orientadas al respeto y la obediencia, fundan las heteroidentificaciones y adscripciones de "ser buenas madres" como colectivo. Hemos vista también el conjunto de estrategias que se despliegan cuando se asocian negativamente formas de ejercer la maternidad, por ejemplo, mostrando diversidad entre migrantes bolivianas para diferenciarse entre paisanas.

Por otra parte, como se analizó con relación a la categoría "alumnas", los sentidos de valorización de la educación se conectan, en los distintos relatos, con la decisión de las mujeres bolivianas de retomar o iniciar la primaria. Hecho que reforzamos con las entrevistas que realiza la escuela para adultos del barrio a las ingresantes de dicha institución en los que se expresa que un grupo mayoritario de las mujeres bolivianas decide comenzar a estudiar para ayudar a sus hijos con las tareas de la escuela.

En particular destacábamos la falsa dicotomía que en principio establecíamos entre ser alumnas en la escuela de adultos y ser madres de alumnos en la escuela y el jardín de niños, porque las obligaciones en relación al cuidado de menores no son abandonadas durante la propia escolarización. En relación a este aspecto, pudimos dar cuenta de una aparente relación cíclica entre "aprender para enseñar" atravesada por "aprender cuidando". En este sentido, la presencia y permanencia en las instituciones está profundamente vinculada a la propia inserción en la sociedad local, dotando de diversas formas los sentidos del habitar cada uno de esos espacios escolares.

\section{Referencias citadas:}

Beheran, M. (2011): "Intersecciones entre trayectorias migratorias, escolares y laborales de jóvenes bolivianos y paraguayos residentes en un barrio del sur de la ciudad de Buenos Aires.", en: Novaro, G. coord., La interculturalidad en debate. Experiencias formativas y procesos de identificación en niños indígenas y migrantes, Buenos. Aires, Biblos, pp.225-244

Bologna, E. y Falcón, M. (2012): “Tendencias de la migración peruana y boliviana en Córdoba. Un análisis a partir de datos censales", en actas del V Congreso de la Asociación Latinoamericana de Población, Montevideo.

Bourdieu, P. (1990): Sociología y cultura, México, 
Grijalbo.

Brubaker, R. y Cooper, F. (2001): "Más allá de `identidad" ", Apuntes de Investigación, V (7)

Caggiano, S. (2008): "Racismo, fundamentalismo cultural y restricción de la ciudadanía: formas de regulación social frente a los inmigrantes en Argentina.”, en M. Novick, , comp., Las migraciones en América Latina, Buenos Aires, CLACSO, pp. 31-51

Cerruti, M. y Binstock G. (2012): Los estudiantes inmigrantes en la escuela secundaria. Integración y desafíos, Buenos Aires, UNICEF.

CENPA (2009): Proyecto Creer y Ser "Conociéndonos", Proyecto inédito, Córdoba.

Domenach, H. y Celton, D. (1998): La Comunidad Boliviana en Córdoba, caracterización y proceso migratorio, Córdoba, ORSTOM, CEA.

Domenech, E. (2010): “Etnicidad e inmigración: ¿hacia nuevos modos de integración en el espacio escolar?", Astrolabio 1(1).

Diez, M. L. (2011): “Biografías no autorizadas en el espacio escolar. Reflexiones en torno a ser migrantes en la escuela.", en: G. Novaro, coord., La interculturalidad en debate. Experiencias formativas y procesos de identificación en niños indígenas y migrantes, Buenos. Aires, Biblos, pp 153-178.

Elias Norbert (2003): "Ensayo acerca de las relaciones entre establecidos y forasteros" en Revista Española de Investigaciones Sociológicas, 104(3), pp. 219-251.

Gago, A. y Maggi, M. F. (2018): “Trayectorias socio-educativas de jóvenes migrantes en Córdoba y Comodoro Rivadavia (Argentina)". Actas del XII Reunión de Antropología del Mercosur. Tomo I. Posadas, Argentina, Facultad de Humanidades y Ciencias Sociales, Universidad Nacional de Misiones.

Grimson, A. (2006): "Nuevas xenofobias, nuevas políticas étnicas en Argentina", en Grimson, A. y Jelin, E. comp, Migraciones regionales hacia la Argentina: Diferencia, desigualdad y derechos, Buenos Aires, Prometeo.

Grimson, A. (2011): Los límites de la cultura. Crítica de las teorías de la identidad. Buenos Aires, Siglo XXI Editores.

Hall, S. (2003): "Introducción: ¿quién necesita identidad?", en: Hall, S y P. du Gay, Cuestiones de identidad cultural, Buenos Aires, Amorrortu Editores, pp 13-39.

Luykx, A. (2000): "Gender Equity and Interculturalidad. The Dilemma in Bolivian Education", en The Journal of Latin America Anthropology. 5 (2) pp. 150-178

Maggi, M. F. (2016): "La cuestión generacional en los estudios migratorios. El caso de jóvenes migrantes e hijos/as de migrantes en la ciudad de Córdoba.", en Actas II Congreso de la Asociación Argentina de Sociología- Pre ALAS 2017, Ciudad de Villa María, Córdoba, Universidad Nacional de Villa María. 
Maggi, M. F. (2018): “La 'seño' de visita. Interpelaciones del campo en clave interseccional". en: Ortiz, C. I. y Oliva, A. coord., Bolivia-Argentina: perspectivas metodológicas de su investigación, Córdoba, Tinta Libre Ediciones, pp. 99-123

Maggi, M. F. y Trabalón C. (2014): Un estudio de caso sobre los procesos identitarios de mujeres bolivianas en un barrio periférico de Córdoba. Trabajo Final de Grado Lic. Sociología inédito, Universidad Nacional de Villa María, Córdoba.

Maggi, M. F. y Trabalón C. (2015): "Interculturalidad y disputas simbólicas. Construcciones de sentido en prácticas y representaciones de argentinos y bolivianos en un barrio periférico de la ciudad de Córdoba", Odisea. Revista de Estudios Migratorios del IIGG, $1(2)$, pp. 239-364.

Magliano, M. J. (2007): “Migraciones de mujeres bolivianas hacia Argentina: cambios y continuidades en las relaciones de género". Revista Amerique Latine Histoire et Mémoire. Les Cahiers ALHIM 14. 1-17

Neufeld, M.R. y Thisted, J. A. (1999.): “De eso no se habla...." Los usos de la diversidad en la escuela, Buenos Aires, Eudeba.

Novaro, G. (2011): “Interculturalidad y Educación. Reflexiones desde las experiencias formativas de niños indígenas y migrantes" en: Novaro, G. coord., La interculturalidad en debate. Experiencias formativas y procesos de identificación en niños indígenas y migrantes, Buenos. Aires, Biblos, pp 15-34.
Novaro, G. (2014): “Procesos de identificación nacional en población migrante: continuidades y quiebres en las relaciones intergeneracionales", Revista de Antropología Social, (23), pp. 157-179.

Novaro, G. y Diez, M. L. (2011): “¿Una inclusión silenciosa o las sutiles formas de la discriminación? Reflexiones a propósito de la escolarización de niños bolivianos.", en: Courtis, C. y Pacecca, M. Discriminaciones étnicas y nacionales: un diagnóstico participativo, Buenos Aires, Editores del Puerto y ADC, pp. 199-230.

Pizarro, C (2011): “Introducción”, en Pizarro, C., ed "Ser Boliviano" en la región metropolitana de la ciudad de Córdoba. Localización socio-espacial, mercado de trabajo y relaciones interculturales, Córdoba, EDUCC.

Sinissi, L. (1998): "'Todavía están bajando del cerro'. Condensaciones estigmatizantes de la alteridad en las representaciones docentes", en Actas ler Congreso Virtual de Antropología y Arqueología.

\section{Fuentes secundarias:}

DGEyC (2008): Censo Provincial de Población 2008, Córdoba.

INDEC (2010). Censo nacionales de Población, Hogares y Viviendas 2010.

\section{Notas:}

${ }^{1}$ Tanto para las entrevistas semiestructuradas como 
para las entrevistas en profundidad, la estrategia de definición muestral fue la de muestreo de la bola de nieve: la selección de los entrevistados se realiza arbitrariamente a partir de la selección de informantes claves institucionales, siendo éstos los conocedores que derivarán, a partir de su relato, a los siguientes informantes. El número de entrevistas tuvo en cuenta como criterio la "saturación de la muestra", es decir, se consideró finalizada la muestra de entrevista por cada grupo definido (agentes institucionales, vecinos argentinos y mujeres bolivianas), cuando éstas coincidían sostenidamente. Como herramienta de interpretación del análisis cualitativo recurrimos a distintas técnicas de codificación. Cabe mencionar por último que el abordaje de los procesos identitarios se realizó desde una perspectiva relacional.

2Para un análisis detenido en las implicancias metodológicas de nuestra presencia como investigadoras y docentes, véase Maggi (2018).

3Dirección General de Estadísticas y Censos de la Provincia de Córdoba (2008)

${ }^{4} \mathrm{El}$ mismo se ha establecido en distintas locaciones de la zona sur de la ciudad desde el año 2001, hasta instalarse definitivamente en la escuela primaria del barrio "boliviano" desde 2004. Allí funcionó en un sector del comedor (lo que implicaba que los procesos de enseñanza y aprendizaje quedaran expuestos a las interferencias del servicio de almuerzo, merienda, limpieza del salón). Tras los sucesivos reclamos de docentes y alumnas, que se sumaron a los pedidos por las condiciones edilicias del primario de niños (con toma de la institución en el proceso de deman- da), recién a partir del año 2013 se dispone de tres aulas nuevas destinadas durante el horario de cursado (13 a 17 horas) al dictado de cada uno de los ciclos del CENPA.

${ }^{5}$ De aquí en adelante, haremos referencia a "los" alumnos para simplificar la redacción y lectura del escrito reconociendo la limitación de esta decisión y esperando en próximos escritos adoptar un lenguaje inclusivo.

${ }^{6}$ En algunos espacios las actividades son organizadas y coordinadas conjuntamente con el Centro de Salud del barrio, como es el caso de los talleres de Salud, de Huerta y de Hilado Artesanal.

${ }^{7}$ Mientras que este porcentaje es del $26 \%$ en varones (5\% nunca asistió; y el 21\% no completó la primaria); y en la población local es del $24 \%$ en mujeres ( $15 \%$ nunca asistió; y el $9 \%$ no completó la primaria); y $25 \%$ en varones (16\% nunca asistió; y el 9\% no completó la primaria). Fuente: Censo provincial 2008 (DGEyC Prov. Córdoba).

8Respecto al nivel educativo y siguiendo la agrupación en niveles que determina la modalidad educativa para jóvenes y adultos, 6 (25\%) se encuentran en el nivel Alfabetización; 8 (33 \%) están en el nivel intermedio; y 11 (42\%) asisten al $2^{\circ}$ ciclo.

${ }^{9} \mathrm{El}$ porcentaje de personas que repitió 3 veces (4\%) corresponde a un alumno en esta condición.

10En un trabajo abocado a la escolaridad de mujeres en contextos andinos en Bolivia, Aurolyn Luykx (2000) 
problematiza la persistencia de estas asimetrías, en relación a las injerencias de agencias internacionales de financiamiento y la supuesta contradicción entre programas de educación intercultural y programas con perspectiva de género.

${ }^{11 U n}$ análisis en detalle del caso se realiza en Gago y Maggi (2018)

${ }^{12}$ Las preguntas durante el diagnostico eran abierta, por ende las respuestas fueron agrupadas por similitud.

${ }^{13} \mathrm{El}$ efecto de la fotografía es adrede, a los fines de preservar en el anonimato a los fotografiados

${ }^{14}$ Pese a esto, es importante resaltar la notable baja en los porcentajes de las tasas de escolarización de jóvenes migrantes bolivianos entre el nivel primario y secundario por encima de la media local. Al respecto se observa que la tasa de bolivianos pasa de $92,6 \%$ para el grupo etario de 10 a 14 (mientras que para la matrícula total de la ciudad es del $97,9 \%$ ) a un 55,2\% de asistencia para los jóvenes bolivianos de 15 a 19 años (frente a una 70,3\% de la ciudad) (Maggi, 2016). Esta disminución de asistencia en el nivel secundario de migrantes de este origen, considerando las apuestas familiares, nos invitan a preguntarnos por las experiencias que dichos jóvenes vivencian en los espacios escolares. 